\title{
Low Rank Coal Pre-treatment to Increase Its Reactivity Towards Gasification with Biomass
}

\author{
Jenny Rizkiana*, Ryzka Pranata, Hasna Nisrina Fauzi, Winny Wulandari, Dwiwahju Sasongko \\ Department of Chemical Engineering - Institut Teknologi Bandung, Jalan Ganeca 10 Bandung 40132, Indonesia
}

\begin{abstract}
Coal can be used to produce hydrogen through steam gasification process. Indonesia has abundant coal reserves and thus hydrogen production from coal is very attractive. However, steam gasification of coal usually requires high temperature due to its low volatile content. The use of catalyst, such as alkaline and alkaline earth metal (AAEM) may promote the hydrogen production. AAEM metal can be found in biomass and thus co-gasification of coal and biomass may become the attractive solution as the AAEM may volatilize during gasification and catalyze the coal when it attaches to the coal surface. However, the presence of silicate may decrease catalytic activity of the attached AAEM and thus it needs to be removed by deashing process. This research aims to determine the effect of the solution type, solution concentration, reaction temperature, and reaction time of coal deashing. The results showed that deashing process decreased the ash content of coal to some extent proved by the gravimetric analysis result. The decrease of ash content also affected to the surface morphology of the coal as some pores are formed and thus the surface area of coal increased slightly. The increase of surface area allows more AAEM to be attached to the coal surface so that the coal may become more reactive towards steam gasification.
\end{abstract}

\section{Introduction}

Indonesia has abundant coal reserves. Unfortunately, $92 \%$ of Indonesian coals are low rank, such as subbituminous and lignite [1]. Low rank coal has high moisture content and low calorific value. Despite the disadvantages, coal is still widely used in Indonesia as main energy sources because of its low price. Generally, coal is used by burning to produce heat as main energy sources, so it causes bad impact to environment. Gasification is considered as an effective way to utilize coal cleanly [2].

Gasification is a thermal conversion process which convert carbon-contain material into synthesis gas. The material may be coal or biomass. Gasification process occurs in several stages, which are drying, pyrolysis, combustion, and gasification [3]. Products of gasification are hydrogen, carbon monoxide, carbon dioxide, and methane [4]. In general, gasification involves the reaction of carbon with gasifying agent at temperature $700^{\circ} \mathrm{C}$ or more to produce heat or feedstock for chemical industry, liquid fuel or other gaseous materials [5]. In gasification process occurs the following reactions.

$$
\begin{gathered}
\mathrm{C}+\mathrm{O}_{2} \rightarrow \mathrm{CO}_{2} \\
\mathrm{C}+0.5 \mathrm{O}_{2} \rightarrow \mathrm{CO} \\
\mathrm{C}+\mathrm{CO}_{2} \rightarrow 2 \mathrm{CO} \\
\mathrm{C}+\mathrm{H}_{2} \mathrm{O} \leftrightarrow \mathrm{CO}+\mathrm{H}_{2}
\end{gathered}
$$

$$
\mathrm{CO}+\mathrm{H}_{2} \mathrm{O} \leftrightarrow \mathrm{CO}_{2}+\mathrm{H}_{2}
$$

As mentioned above, majority of Indonesian coals are low rank coal. Low rank coal gasification has low efficiency and low carbon conversion [6]. However, gasification of low rank coal still can be accomplished by the addition of catalyst.

Co-gasification of coal with biomass can increase the carbon conversion, especially hydrogen [2]. Catalytic effect on co-gasification process caused by alkali and alkaline earth metal (AAEM) that can be found in biomass ash. In biomass, alkali and alkaline earth metal formed as carbonate. Alkali and alkaline earth metal that formed as carbonate can increase carbon conversion in gasification process through following reaction [7].

$$
\begin{aligned}
& \mathrm{M}_{2} \mathrm{CO}_{3}+2 \mathrm{C} \rightarrow 2 \mathrm{M}+3 \mathrm{CO} \\
& 2 \mathrm{M}+2 \mathrm{H}_{2} \mathrm{O} \rightarrow 2 \mathrm{MOH}+\mathrm{H}_{2} \\
& 2 \mathrm{MOH}+\mathrm{CO} \rightarrow \mathrm{M}_{2} \mathrm{CO}_{3}+\mathrm{H}_{2}
\end{aligned}
$$

where $\mathrm{M}$ is an alkali and alkaline earth metal

However, coal contains silicone in the form of silica, a compound that could deactivate catalyst. Risnes et al. [8] found that silica could deactivate catalytic activity of AAEM by forming silicate, which has no catalytic activity.

Steel et al. [9] proved that silica content in coal could be decreased by leaching method using acid solution. Leaching method is done by mixing coal with acid solution at a certain temperature and time. By reducing

\footnotetext{
Corresponding author: $\underline{\text { r@@che.itb.ac.id }}$
} 
silica content, co-gasification process is expected to be more efficient which resulting higher carbon conversion.

The present study is done to find the suitable condition to deash low rank coal. The conditions include acid solution type, acid concentration, temperature, and residence time. Deashing performance is evaluated by comparing the ash content of raw coal sample with the deashed ones.

\section{Material and Methods}

\subsection{Feedstock preparation}

Indonesian low rank coal was used as the feedstock sample. The samples were ground and sieve to particle size of 14-28 mesh (about 0.595-1.19 mm) and dried in the oven at $110^{\circ} \mathrm{C}$ overnight.

\subsection{Coal pre-treatment}

The samples were leached with two kinds of strong acid solution, i.e. $\mathrm{HF}$ and $\mathrm{HCl}$. The sample mass and solution volume used in all leaching experiments was $10 \mathrm{~g}$ and $250 \mathrm{ml}$, respectively. Experiments were performed at ambient temperature $\left(25^{\circ} \mathrm{C}\right)$, medium temperature $\left(47^{\circ} \mathrm{C}\right)$ and high temperature which were below the boiling points of the mixtures $\left(70^{\circ} \mathrm{C}\right)$. Experiments using $\mathrm{HCl}$ were performed in a $500 \mathrm{ml}$ glass beaker, while experiments using HF were performed in $500 \mathrm{ml}$ Teflon beaker. All experiments were mounted on an electric hotplate with magnetic stirring device. There were three variations of reaction residence time of leaching, i.e. 2, 3 and 4 hours. After leaching, the mixtures were immediately filtered by Büchner funnel (vacuum filtration) for experiments using $\mathrm{HCl}$, and it filtered by Polypropylene funnel for experiments using HF. The filtered cakes were washed with distilled water until the wash water became neutral. Filter cake residues were placed in an oven at $110^{\circ} \mathrm{C}$ overnight to remove water as a final drying step.

\subsection{Analysis}

The samples were burned in the furnace at $700^{\circ} \mathrm{C}$. The ash content of coal was calculated by using the following formula:

$$
\text { ash content }=\frac{\text { mass of ash }}{\text { mass of sample }} \times 100 \%
$$

The ash content of leached samples compared with the ash content of raw sample. The differences of ash content of leached samples and raw sample were used to analyze whether the leaching experiments succeed or not and how was the best condition of leaching experiments should be done.

\section{Results and Discussion}

Leaching method using acid solution ( $\mathrm{HCl}$ and $\mathrm{HF}$ ) could decrease ash content in coal as shown in Fig. 1 and 2. The ash content of raw sample is $8.39 \%$.

Ash content in coal sample could decrease approximately $20-23 \%$ weight compared to the ash content of raw sample by leaching method using $\mathrm{HCl}$. Fig. 1(a) shows ash content of raw sample and leached samples at different $\mathrm{HCl}$ concentration. However, the increase of $\mathrm{HCl}$ concentration in leaching experiments did not affect the ash content significantly. Similar result was also obtained by Steel et al. [9]. They found that dissolution of mineral matter isolated from coal with $\mathrm{HCl}$ slightly increased as the increase of $\mathrm{HCl}$ concentration. Fig. 1(b) shows ash content of raw sample and leached samples at different temperature. The increase of temperature in leaching experiments with $\mathrm{HCl}$ also did not affect the ash content significantly. Steel et al. also did leaching experiments with various temperatures, i.e. $20^{\circ} \mathrm{C}, 70^{\circ} \mathrm{C}$, and $100^{\circ} \mathrm{C}$. They found that ash content at temperature $20^{\circ} \mathrm{C}$ and $70^{\circ} \mathrm{C}$ not much different. However, the dissolution increases slightly when reaction temperature is raised to $100^{\circ} \mathrm{C}$. Fig. $1(\mathrm{c})$ shows ash content of raw sample and leached samples at different residence time. Same with the previous result, the increase of residence time did not affect the ash content significantly.

Ash content in coal sample could be decreased approximately $47-59 \%$ weight compared to the ash content of raw sample by leaching method using HF. Fig. 2(a) shows ash content of raw sample and leached samples at different HF concentration. The ash content of sample decreased with the increase of HF concentration. Steel et al. [9] found that the ash content of leached sample decreased as the HF concentration increased. The result of leaching experiments using HF conducted by Steel could decrease the ash content of sample up to $96 \%$. Fig. 2(b) shows ash content of raw sample and leached samples at different temperature. The increase of temperature in leaching experiments with HF also decreased the ash content of sample. Steel et al. also did leaching experiments with various temperatures, i.e. $20^{\circ} \mathrm{C}$ and $65^{\circ} \mathrm{C}$. They found that the increase of temperature could decrease ash content of sample significantly. At $20^{\circ} \mathrm{C}, 96 \%$ by weight of sample dissolve using $14 \mathrm{M} \mathrm{HF}$, and at $65^{\circ} \mathrm{C}, 95 \%$ by weight of the sample dissolves using only approximately $1.5 \mathrm{M}$ HF. Fig. 2(c) shows ash content of raw sample and leached samples at different residence time. The increase of residence time did not affect the ash content significantly. The ash content of sample at residence time of 3 hours is approximately $4.1 \%$ and the ash content did not change at residence time of 4 hours. Accordance with Steel et al. [9], the equilibrium with respect to dissolution of aluminosilicates using $\mathrm{HF}$ is established at residence time of 3 hours. 


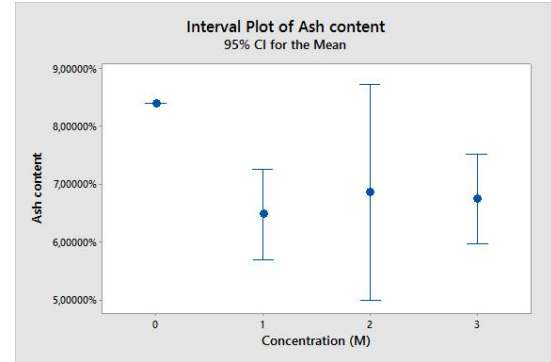

(a)

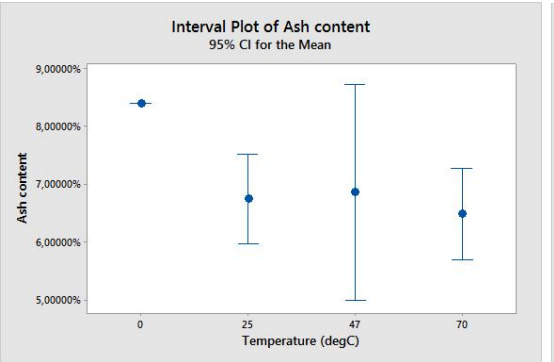

(b)

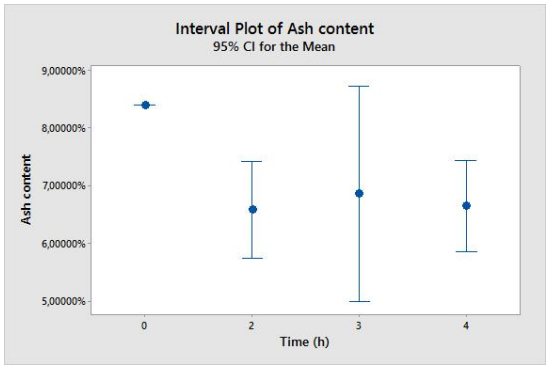

(c)

Fig. 1. Comparison of ash content range of leaching experiments using $\mathrm{HCl}$ with various (a) $\mathrm{HCl}$ concentration, (b) temperature, (c) residence time.

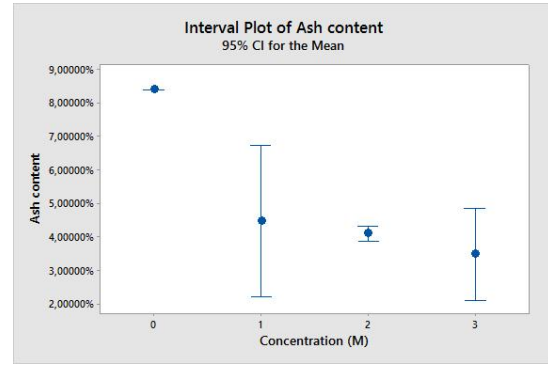

(a)

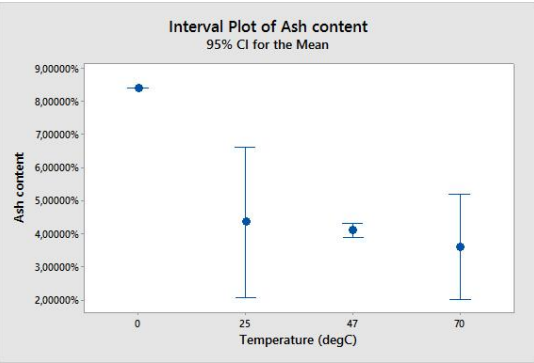

(b)

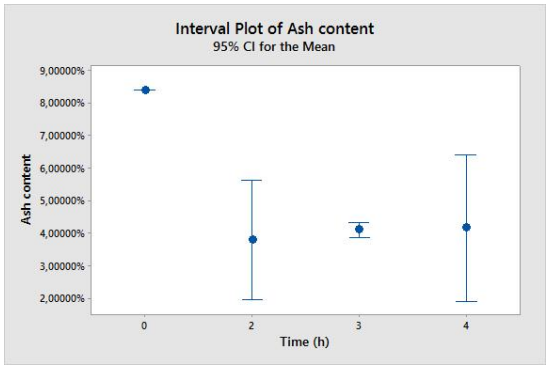

(c)

Fig. 2. Comparison of ash content range of leaching experiments using HF with various (a) HF concentration, (b) temperature, (c) residence time.

Fig. 3 shows comparison of ash content in leaching experiments using $\mathrm{HCl}$ and $\mathrm{HF} 3 \mathrm{M}$. Fig. 3 shows that leaching experiment using HF more effective to decrease the ash content of sample compared to $\mathrm{HCl}$. The ash content of leached sample using $\mathrm{HCl}$ solution is in range $6.0-7.5 \%$, and the average is $6.7 \%$. Meanwhile, the ash content of leached sample using HF solution is in range $2.1-4.9 \%$, and the average is $3.5 \%$. At acid concentration of $3 \mathrm{M}, \mathrm{HCl}$ could decrease ash content in the amount of $20 \%$, and HF could decrease ash content in the amount of $59 \%$.

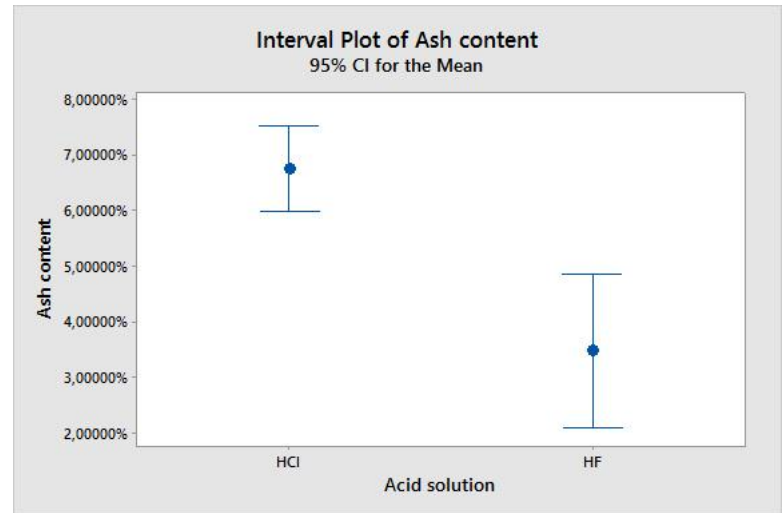

Fig. 3. Comparison of ash content in leaching experiments with acid concentration of $3 \mathrm{M}$.

Das et al. [10] found that leaching experiments using $\mathrm{HCl}$ effective to removes $\mathrm{Na}, \mathrm{K}, \mathrm{Mg}, \mathrm{Ca}$, and $\mathrm{Al}$, while HF removes almost all the ash elements. Steel et al. [9] also found that $\mathrm{HCl}$ dissolves essentially all of $\mathrm{Na}, \mathrm{Ca}$, $\mathrm{Mg}, \mathrm{Fe}$, and some of the $\mathrm{Al}, \mathrm{K}$, and Ti. Essentially, no $\mathrm{Si}$ is exctracted from the mineral matter by leaching experiments using $\mathrm{HCl}$. Meanwhile, $\mathrm{HF}$ is extremely effective at reacting with most of the minerals which occur in coal. In this experiments, the mineral matter that expected to be decreased from coal sample is silica. Si could be removed from sample effectively by $\mathrm{HF}$ solution with $\mathrm{SiF}_{4} .2 \mathrm{H}_{2} \mathrm{O}$ formation in aqueous or gas phase.

\section{Conclusion}

This paper has shown that $\mathrm{HCl}$ and $\mathrm{HF}$ could decrease ash content of coal. However, HF is more effective at decreasing the ash content of Indonesian low rank coal. Leaching experiments using $\mathrm{HCl}$ with different concentration, temperature, and residence time did not affect the ash content of coal significantly. Meanwhile, leaching experiments using $\mathrm{HF}$ could improve the decreasing ash content with the increase of acid concentration and temperature.

$\mathrm{Si}$ inhibited the catalytic activity of co-gasification, so it is expected that Si could disappear from the coal in order to increase carbon conversion. However, in this leaching experiments, $\mathrm{Si}$ was not the only element that decreased from coal. Hence, the co-gasification of pretreatmented coal with biomass should be done to prove the catalytic effects so the co-gasification product, i.e. synthesis gas especially hydrogen increased.

\section{References}

1. Badan Pengkajian dan Penerapan Teknologi (BPPT), "Outlook Energi Indonesia 2016", Jakarta:Perpustakaan Nasional RI (2016)

2. J. Rizkiana, G. Guan, W.B. Widayatno, X. Hao, X. Li, W. Huang, A. Abudula, Applied Energy, 133,

* Corresponding author: jr@che.itb.ac.id 
282-288 (2014).

3. S. Farzad, M.A. Mandegari, J.F. Gorgens, Biofuel Res. J., 12, 483-495 (2016).

4. U. Arena, Waste Management 32 (2012), 625-639.

5. A.H. Demirbas, I. Demirbas, Energy Conv. Manage., 48, 2386-2398 (2007).

6. W. Duan, Q. Yu, J. Liu, T. Wu, F. Yang, Q. Qin, Energy 111, 859-868 (2016).

7. H. Iwaki, S. Ye, S. Katagiri, K. Kitagawa, Appl. Cat. A: General 270, 237-243 (2004).

8. H. Risnes, J. Fjellerup, U. Henriksen, A. Moilanen, P. Norby, K. Papadakis, Fuel, 82, 641-651 (2003).

9. K.M. Steel, J. Besida, T.A. O’Donnel, D.G. Wood, Fuel Process. Technol., 70, 171-192 (2001).

10. P. Das, A. Ganesh, P. Wangikar, Biomass and Bioenergy, 27, 445-457 (2004). 